\title{
The effects of social stimuli on psychophysiological reactivity to an aversive film*
}

\author{
DAVID C. GLASS \\ Russell Sage Foundation and New York University, New York, N.Y. 10003 \\ ANDREW GORDON \\ Northwestern University, Evanston, Ill. 60201 \\ and \\ THOMAS HENCHY \\ New York University, New York, N.Y. 10003
}

Stress was induced by an aversive film, and stress responses were measured by tonic skin conductance and self-reports of tension. Contrary to initial expectations, skin conductance levels were greater in the presence of a friend than in the presence of a stranger and greater than in a condition where $S$ s watched the film alone. The results also showed that a friend who was blocked from view produced higher levels of skin conductance and subjective tension than did a friend who was visible to the $S$, whereas the effect was just the opposite for visible and nonvisible strangers. Both sets of findings were interpreted in terms of conflicting needs for anonymity and emotional comparison.

Kissel (1965) has recently shown that tonic skin conductance responses to a stressful task situation were lower in the presence of another person than when the $\mathrm{S}$ worked alone. However, stress reduction was significant only if the other person was a friend, that is, someone with whom the $S$ had previously interacted. Strangers did not alter level of reactivity appreciably. These results have been explained by assuming that friends provide greater satisfaction of desires for reassurance and sympathy than do strangers.

A likely determinant of the effectiveness of friends in providing such satisfaction is the extent to which they are actually available to one another. Blockage of both visual and verbal contact between victims might seriously reduce the opportunity for reassurance cues to be communicated. Under these circumstances we would expect friends and strangers to be equally ineffective in reducing stress (cf. Wapner \& Alper, 1952). On the other hand, if there is at least visual contact between individuals experiencing stress, we would expect greater stress reduction among friends than among strangers. The present study was designed to test these hypotheses.

\section{SUBJECTS AND PROCEDURE}

The Ss were 78 paid male undergraduates recruited through an advertisement in a local newspaper. Stress was induced by exposing them to a $17-\mathrm{min}$

*The research reported in this paper was made possible by grants from the National Science Foundation (GS-1354) and from the Russell Sage Foundation. Our gratitude goes to Michael Cantor who served as "the stranger." Thanks are also due to Sharon Kaufman and Elke Epstein for their assistance in the statistical analyses. We appreciate the comments of Ladd Wheeler who examined an earlier draft of this paper. silent film called "Subincision," which depicts an aboriginal puberty rite involving mutilation of the genitals of adolescent boys (Lazarus \& Opton, 1966).

At the beginning of the experimental session, each $S$ was told that the purpose of the study was to investigate his "psychological and physiological reactions to a silent film." After attaching skin electrodes to the $S$ 's fingers, he was asked to "relax for about $20 \mathrm{~min}$ in order to give the electrode jelly a chance to make good contact with your skin." This period was actually used to allow time for hydration, with the last minute being used to record the $S$ 's resting-level autonomic reactivity. Skin resistance was measured with a Beckman Type R Dynograph recorder, a Type 9892A GSR coupler, and Beckman biopotential electrodes.

After resting level had been recorded, the lights were turned out, and the movie projector was activated. When the film was over, the $S$ completed a set of rating scales, and the session was terminated.

\section{DEPENDENT MEASURES}

The main dependent variable was level of tonic skin conductance during film viewing. Following the general recommendations of Lazarus (for example, Lazarus \& Opton, 1966), five critical periods in the continuous skin resistance record were sampled. Each period corresponded to a stressful mutilation scene in the film. Four readings were also taken for each $\mathrm{S}$ every $15 \mathrm{sec}$ during the I-min resting level period at the beginning of the experimental session.

A second dependent measure was each $S$ 's postfilm rating of his feelings of tension during the film.

EXPERIMENTAL CONDITIONS Alone (A) Condition

The $S s$ in this condition were treated exactly as described in the procedure section above.

Visible Stranger (VS) Condition

The VS Ss were treated like A Ss, except that a confederate of the $E$ was introduced as another $S$. The confederate and $S$ were seated side by side and both were treated identically by the $\mathrm{E}$. Talking or explicit signaling of any kind was prohibited throughout the session.

Nonvisible Stranger (NVS) Condition

This condition was the same as VS, except that a screen was moved into place to separate the $S$ and confederate at the very beginning of the experimental session.

Visible Friend (VF) Condition

The Ss assigned to this condition were contacted in advance of their appointment and asked to bring a friend with them-"another male undergraduate friend of yours"-when they appeared for the experiment. Although the friend went through the same procedure as the critical S, "dummy" electrodes were attached, and his autonomic responses were not actually recorded.

Nonvisible Friend (NVF) Condition

The Ss in this condition also brought a friend to the experimental session. However, instead of sitting in view of one another during the film, they were separated by the screen used in the NVS condition.

Skin Conductance Reactivity

There were no differences in the averages of the four resting-level skin conductance readings taken at the beginning of the experiment, that is, about $20 \mathrm{~min}$ after the $\mathrm{Ss}$ were seated in the laboratory. Nevertheless, skin conductance reactivity scores during film viewing were covariance adjusted to take account of whatever individual differences did exist in initial resting levels.

Every $S$ received five stress reactivity scores, each based on the average of his three highest conductance responses to each of five mutilation scenes. The covariance-adjusted means and standard deviations of these averages are presented in Table 1. Analysis of variance of these results for all five experimental groups yielded significant effects due to conditions $(F=5.74, d f=4 / 67, p<.01)$, successive operations scenes $(F=10.85$, $\mathrm{df}=4 / 268, \mathrm{p}<.01)$, and an interaction between conditions and operations $(F=1.99, \quad d f=16 / 268, p<.05)$. A subsequent 2 by 2 variance analysis eliminating $A$ Ss revealed a main effect due to friend-stranger $(F=13.54, \mathrm{df}=1 / 55$, $\mathrm{p}<.01)$, an interaction between this variable and visibility-nonvisibility $(\mathrm{F}=4.47, \mathrm{df}=1 / 55, \quad \mathrm{p}<.05)$, and an interaction between operation scenes and visibility $(F=3.54$, df $=4 / 220, p<.05)$. 
Table 1

Means and Standard Deviations of Adjusted Skin Conductance Reactivity Scores (in Microohms)

\begin{tabular}{|c|c|c|c|c|c|c|c|c|c|c|c|c|}
\hline \multirow{3}{*}{$\begin{array}{l}\text { Experimental } \\
\text { Condition }\end{array}$} & \multicolumn{10}{|c|}{ Operation Stenes } & & \\
\hline & \multicolumn{2}{|c|}{1} & \multicolumn{2}{|c|}{2} & \multicolumn{2}{|c|}{3} & \multicolumn{2}{|c|}{4} & \multicolumn{2}{|c|}{5} & \multicolumn{2}{|c|}{ Average } \\
\hline & Mean & SD & Mean & $\mathrm{SD}$ & Mean & $\mathrm{SD}$ & Mean & $\mathrm{SD}$ & Mean & SD & Mean & SD \\
\hline A & 17.91 & 5.36 & 17.87 & 5.44 & 19.61 & 6.58 & 20.33 & 7.62 & 20.64 & 7.97 & 19.27 & 6.59 \\
\hline VS & 20.72 & 3.57 & 20.10 & 2.35 & 21.14 & 2.70 & 21.59 & 4.06 & 21.16 & 3.96 & 20.94 & 3.33 \\
\hline NVS & 16.80 & 6.24 & 15.06 & 5.06 & 15.35 & 6.48 & 16.51 & 5.90 & 16.27 & 5.29 & 16.00 & 5.79 \\
\hline VF & 22.05 & 8.90 & 21.27 & 7.41 & 23.66 & 11.48 & 26.11 & 11.37 & 25.28 & 10.13 & 23.67 & 9.86 \\
\hline NVF & 28.05 & 6.25 & 27.10 & 5.51 & 26.19 & 4.49 & 27.75 & 8.38 & 28.09 & 8.36 & 27.43 & 6.60 \\
\hline
\end{tabular}

These results are based on five skin conductance scores, but they correspond rather closely to the continuous pattern of conductance changes over the $17 \mathrm{~min}$ of the entire film.

Subjective Tension

Immediately after film viewing, all Ss responded to the following questionnaire item: "How tense or uneasy did you feel during the film?" Ratings were made on a 51-point scale. Analysis of variance of these ratings revealed a significant interaction between friend-stranger and visibility-nonvisibility $(\mathrm{F}=4.23, \mathrm{df}=1 / 52$, $\mathrm{p}<.05$ ), which corresponded in direction to the interaction reported for skin conductance. Unlike skin conductance, however, there was no main effect due to friendship. A correlation between the tension ratings and the single highest skin conductance score during all five mutilation scenes was only -.04 .

\section{DISCUSSION}

Skin conductance responses in this study showed that stress was higher in the presence of a friend than in the presence of a stranger. Indeed, stress arousal with a stranger was at about the level obtained for Ss viewing the film alone. These findings are directly opposite to initial expectations of a reduction in stress in the presence of friends. The interaction between friendship and visibility is also inconsistent with our orjginal hypothesis. On both skin conductance and tension ratings, nonvisible friends produced greater arousal to the stressor film than did visible friends, whereas visible strangers produced greater arousal than did nonvisible strangers.

Why does the presence of a friend enhance stress arousal? Why does visibility of a stranger tend to increase stress while visibility of a friend tends to decrease it?
There are undoubtedly a variety of answers to one or both of these questions (for example, Wapner \& Alper, 1952). However, the most likely answer, in our view, is based on the notion of conflicting desires for anonymity and affiliation. Sarnoff \& Zimbardo (1961) report that desires for affiliation decrease following certain kinds of arousal, presumably where repressed motives are in imminent danger of being expressed. The subincision film has been shown to stimulate repressed motives such as castration anxiety and homosexuality (Lazarus \& Opton, 1966). If our $S s$ did in fact become aroused by castration fears, they should, according to Sarnoff and Zimbardo, prefer to be alone. This desire not to affiliate is sufficient to explain the skin-conductance main effect of friend vs stranger. If one does not wish to be identified, the presence of a friend fulfills that need to a lesser extent than does a stranger.

At the same time that desires for anonymity were aroused, needs for emotional comparison were also generated by the stressor film. The need to know how others were experiencing the film was probably an equally strong response among the Ss (Schachter, 1959). However, comparative knowledge of the extent and nature of others' arousal can be gained only at some cost to anonymity. Under these conditions blockage from view of a stranger may be considered a relative gain, since it assures desired isolation from an individual whose unfamiliar reactions probably would not have been useful in satisfying comparison needs. By contrast, blockage from a friend is a relative loss, since it frustrates immediate needs for emotional comparison and also leaves desires for anonymity unsatisfied. This line of reasoning appears to account for the interaction between friendship and visibility.

This experiment has provided evidence that the psychic impact of a stress-arousing event is not a simple function of the mere presence of another. The psychological significance of that other relative to the nature of the stressor appears to be an important determinant of stress arousal and reduction. Our manipulation of friendship was admittedly crude, and future research ought to give closer scrutiny to the operations used to define this variable. Systematic variation of psychological stressors should also be included in subsequent research, for the present results have suggested that the effect of social stimuli on stress response depends very much upon the nature of the stressor.

\section{REFERENCES}

KISSEL, S. Stress-reducing properties of social stimuli. Journal of Personality \& Social Psychology, 1965, 2, 378-384

LAZARUS, R. S., \& OPTON, E. M. The study of psychological stress: A summary of theoretical formulations and experimental findings. In $C$. D. Spielberger (Ed.), Anxiety and behavior. New York: Academic Press, 1966. Pp. 225-262.

SARNOFF, I., \& ZIMBARDO, P. G. Anxiety, $f e a r$ and social affiliation. Journal of Abnormal \& Social Psychology, 1961, 62, 356-363.

SCHACHTER, S. The psychology of affiliation. Stanford: Stanford University Press, 1959.

WAPNER, S., \& ALPER, $\Upsilon$. G. The effect of an audience on behavior in a choice situation. Journal of Abnormal \& Social Psychology, $1952,47,222-229$.

NOTE

1.Ss in this condition were tested several months after completion of the other four conditions. 